
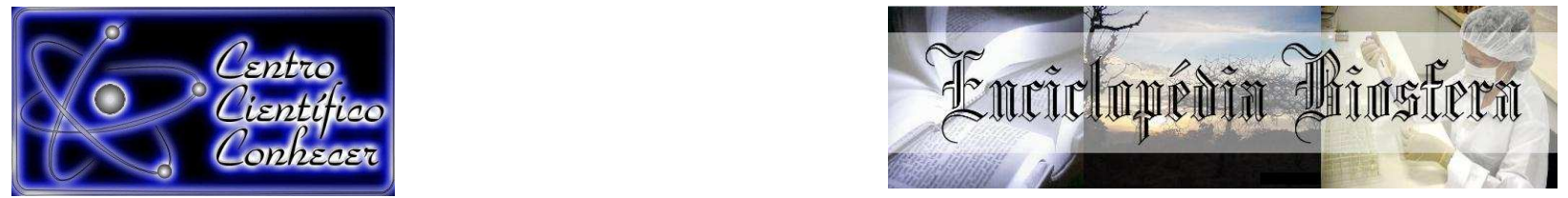

\title{
LOGÍSTICA REVERSA: UM ESTUDO BIBLIOMÉTRICO DE PUBLICAÇÕES NACIONAIS NO PERÍODO DE 2011 A 2015
}

Larissa Juliana Patrocínio da Silva ${ }^{1^{*}}$ Sara da Costa Fernandes ${ }^{2}$ Vagner Rosalem ${ }^{3}$

${ }^{*}$ Autora para correspondência

1. Discente no Mestrado Profissional em Gestão Organizacional, Universidade Federal de Goiás, Regional Catalão. Catalão - GO, Brasil.

(larissajps_@hotmail.com)

2. Discente no Mestrado Profissional em Gestão Organizacional, Universidade

Federal de Goiás, Regional Catalão. Catalão - GO, Brasil.

3. Docente no Mestrado Profissional em Gestão Organizacional, Universidade

Federal de Goiás, Regional Catalão. Catalão - GO, Brasil.

Recebido em: 03/10/2016 - Aprovado em: 21/11/2016 - Publicado em: 05/12/2016

DOI: 10.18677/EnciBio_2016B_189

\begin{abstract}
RESUMO
A Logística Reversa só foi citada pela primeira vez na legislação brasileira, na Lei Federal no 12.305/10 que criou a Política Nacional dos Resíduos Sólidos (PNRS). Este artigo teve como objetivo compreender a evolução da logística reversa nas publicações brasileiras, para isso foi feito um levantamento bibliográfico nos últimos cinco anos. Verificou-se uma variedade de periódicos publicando sobre o tema, distribuição próxima da quantidade de publicação por ano, diversos autores com incidência de repetição baixa. Diversas instituições vinculadas aos autores, até uma estrangeira, mas em sua maioria da região Sudeste e Sul do Brasil. Percebe-se que a Logística Reversa pode ser aplicada em vários setores da economia, mas encontra ainda muitas barreiras e necessidades para se adequar. Muitos artigos relacionaram o tema com a legislação pertinente e principalmente a criação da Política Nacional de Resíduos Sólidos, que foi um marco para a Logística Reversa no Brasil. Muitos artigos também relacionam o tema com reciclagem de materiais, demonstrando assim sustentabilidade e responsabilidade socioambiental por parte das empresas pesquisadas. Esta pesquisa trouxe dados importantes consolidando a Logística Reversa por pesquisadores em publicações nacionais e sendo parte de estratégias de empresas de vários setores, mas ainda deixam lacunas a serem preenchidas por falta de informações, pouca fiscalização, meios físicos e financeiros para a implantação da mesma.
\end{abstract}

PALAVRAS-CHAVE: bibliometria, logística; logística reversa

\section{REVERSE LOGISTICS: A BIBLIOMETRIC STUDY OF NATIONAL PUBLICATIONS IN THE 2011 PERIOD FOR 2015}

\begin{abstract}
The Reverse Logistics was only mentioned for the first time in Brazilian legislation, the Federal Law no 12.305/10 establishing Política Nacional de Resíduos Sólidos (PNRS). This study aimed to understand the evolution of reverse logistics in Brazilian publications, for it was made a literature over the past 5 years. There a variety of
\end{abstract}


journals publishing on the subject close to the amount of publication per year distribution, several authors with low repetition incidence. Several institutions linked to the authors, to a foreigner, but most of the Southeast and South of Brazil. It is noticed that the Reverse Logistics can be applied in various sectors of the economy, but also shows many barriers and needs to suit. Many articles related the theme with relevant legislation and especially the creation of Política Nacional de Resíduos Sólidos, which was a milestone for the Reverse Logistics in Brazil. Many articles also relate the subject with recycling materials, thus demonstrating sustainability and environmental responsibility by the companies surveyed. This research has important data consolidating the Reverse Logistics by researchers in national publications and is part of companies in various sectors strategies, but still leaves gaps to be filled for lack of information, lack of supervision, physical and financial resources for the implementation thereof.

KEYWORDS: bibliometric, logistic; reverse logistic.

\section{INTRODUÇÃO}

Para CHAVES \& BATALHA (2006), com a preocupação ambiental impulsionada na década de 90 , novas abordagens foram introduzidas no conceito de Logística Reversa. Empresas de processamento e distribuição enxergaram na Logística Reversa uma fonte de redução de perdas. Mas a Logística Reversa só foi citada pela primeira vez na legislação brasileira, na Lei Federal no 12.305 (BRASIL, 2010), que criou a Política Nacional dos Resíduos Sólidos (PNRS).

A logística reversa é compreendida como o fluxo de materiais no sentido contrário àquele que vai dos fornecedores de matérias-primas para o usuário (CORRÊA, 2010). Os canais de pós-consumo são concebidos pelo fluxo reverso de produtos que tiveram a utilidade original finalizada e que retornam ao ciclo produtivo de alguma maneira para reuso, remanufatura ou reciclagem, já os canais reversos de pós-venda se constituem pelo retorno de uma parcela de produtos com pouco ou nenhum uso, que fluem no sentido inverso, do consumidor final para o varejista ou fabricante, do varejista para o fabricante ou entre empresas, motivado por problemas relacionados à qualidade, término de validade, estoques excessivos, consignação, etc. (LEITE, 2009).

Produtos que se tornam obsoletos, danificados ou não funcionam devem regressar ao ponto de origem para serem adequadamente descartados, reparados ou reaproveitados (GONÇALVES \& MARINS, 2006). DE BRITO (2004) diz que a logística reversa é diferente da gestão de resíduos, que trata da coleta e tratamento de produtos a serem descartados e suas implicações legais.

LEITE (2002) dividiu o fluxo reverso de bens finais em dois tipos, os bens de pós-consumo e bens de pós-venda. Logística reversa de pós-venda é a área de planejamento, operação e controle do fluxo físico e informações de produtos de pósvenda sem uso ou com pouco uso (LEITE, 2002). Nessa categoria de pós-venda incluem-se erros nos processamento dos pedidos, garantia dada pelo fabricante, defeitos ou falhas no funcionamento do produto, avarias no transporte, mercadorias em consignação, liquidação de estação, pontas de estoque etc. (LEITE, 2009).

O retorno destes produtos que tiveram pouco uso ou nenhum é em virtude de problemas, cuja responsabilidade é do distribuidor ou fabricante, ou ainda por insatisfação do consumidor (CHAVES et al., 2008). Há também o recall de produtos com problemas na validade ou problemas observados após a venda, que são devolvidos por motivos legais ou diferenciação de serviço prestado ao cliente (GUARNIERI et al., 2005). LEITE (2002) classificou devoluções da logística reversa 
pós-venda em três categorias: Comerciais, Garantia/Qualidade e Substituição de Componentes.

Na categoria Comerciais estão as devoluções contratuais e não contratuais. Contratuais são aqueles produtos consignados, substituição de novos produtos, produtos sazonais e embalagens. Já os não contratuais são aqueles por erro do fornecedor em venda direta, erro de expedição ou qualidade no produto pelo consumidor final. Na categoria Garantia/Qualidade estão os produtos com defeitos de fabricação, mau funcionamento, avarias no produto e na embalagem, entre outros. Muitas empresas consertam ou reformam estes produtos para novamente agregarem valor comercial. Por último a categoria de Substituição de Componentes são aqueles que recebem consertos e manutenções ao longo da vida útil (LEITE, 2002).

A logística reversa de pós-consumo se constitui pelo fluxo de materiais e produtos de origem no descarte após finalizada a sua utilidade e que retornam ao ciclo produtivo. Este fluxo se divide em materiais para reciclagem e materiais para reutilização. O de reciclagem é aquele em que os materiais dos produtos descartados são extraídos industrialmente e transforma-se em matérias-primas secundárias ou recicladas para a fabricação de novos produtos. Já a de reutilização é quando os produtos podem ser reaproveitados as partes essenciais apenas substituindo alguns componentes complementares, refazendo um produto com as mesmas características originais (LEITE, 2009).

Este artigo teve como objetivo compreender a evolução da logística reversa nas publicações brasileiras, para isso foi feito um levantamento bibliográfico nos últimos cinco anos.

\section{MATERIAL E MÉTODOS}

Efetuou-se um levantamento bibliográfico relativo ao tema Logística Reversa no ano de 2016. Foram levantados artigos publicados no período de 2011 a 2015 na Base de Dados de Periódicos da Capes e no Scielo com o tema "Logística Reversa" e foram selecionadas apenas Revistas de abrangência nacional e que tivessem publicação online no período de cinco anos, compreendido entre 2011 e 2015. Foram encontrados 117 artigos dos quais foram selecionados aqueles que continham o termo da pesquisa no título, para que fossem utilizados aqueles que focam inteiramente no tema escolhido para o levantamento bibliométrico.

\section{RESULTADOS E DISCUSSÃO}

A metodologia utilizada para atingir os objetivos deste artigo foi através da bibliometria. BRAGA (1974) recomenda esta metodologia como pesquisa.Os índices bibliométricos são empregados para avaliarem a produtividade e a qualidade de pesquisa dos cientistas, por meio da medição com base nos números de publicações e citações de diversos pesquisadores (MEIS et al., 1999).

Foram encontrados 117 artigos no total, dos quais foram selecionados apenas os que continham o termo "Logística Reversa" no título, tendo como resultado 23 artigos no período de 2011 a 2015. Em relação à quantidade de publicações, observou-se que houve publicações em todos os anos pesquisados, com quatro publicações em 2012, 2014 e 2015, cinco publicações em 2011 e em 2013 com a maior quantidade, seis publicações, conforme pode ser observado no Gráfico 1. 


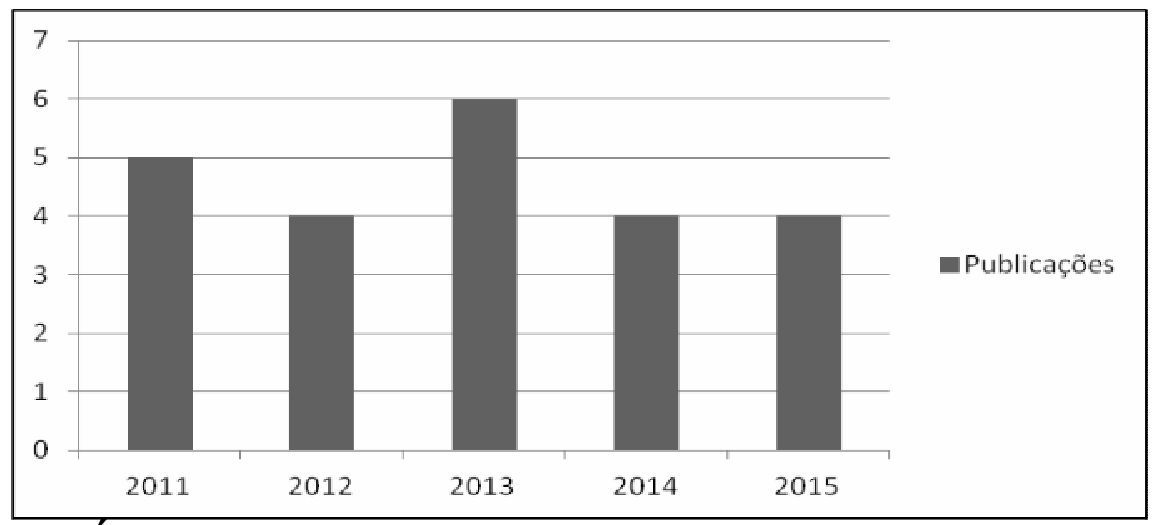

GRÁFICO 1 - Quantidade de publicações por ano

FONTE: elaborado pelos autores (2016)

No Quadro 1 estão distribuídos os periódicos encontrados por ano. Como pode ser observado, cinco periódicos publicaram dois artigos, enquanto os outros apenas um. São estes: o Ambiente \& Sociedade, Gestão Ambiental e Sustentabilidade, Gestão \& Produção, Polímeros e Revista de Administração, Contabilidade e Economia.

QUADRO 1 - Lista de periódicos encontrados com publicações com o tema Logística Reversa durante os anos de 2011 a 2015

\begin{tabular}{|c|l|}
\hline Ano & \multicolumn{1}{|c|}{ Periódico } \\
\hline 2011 & Polímeros \\
\hline 2011 & Revista Diálogo \\
\hline 2011 & PG \& C - Perspectivas em Gestão e Conhecimento \\
\hline 2011 & RAIMED - Revista de Administração IMED \\
\hline 2011 & Desenv. E Meio Ambiente \\
\hline 2012 & RAE - Revista de Administração de Empresas \\
\hline 2012 & RESR - Revista de Economia e Sociologia Rural \\
\hline 2012 & Gestão \& Produção \\
\hline 2012 & Lex Humana \\
\hline 2013 & Journal of Transport Literature \\
\hline 2013 & Gestão \& Produção \\
\hline 2013 & Ambiente \& Sociedade \\
\hline 2013 & RACE - Revista de Administração, Contabilidade e Economia \\
\hline 2013 & GeAS - Gestão Ambiental e Sustentabilidade \\
\hline 2013 & Polímeros \\
\hline 2014 & Ambiente \& Sociedade \\
\hline 2014 & Evidenciação Contábil e Finanças \\
\hline 2014 & RACE - Revista de Administração, Contabilidade e Economia \\
\hline 2014 & HOLOS \\
\hline 2015 & Production \\
\hline 2015 & Engenharia Sanitária e Ambiental \\
\hline 2015 & GeAS - Gestão Ambiental e Sustentabilidade \\
\hline & REGET - Revista Eletrônica em Gestão, Educação e Tecnologia \\
2015 & Ambiental \\
\hline
\end{tabular}

FONTE: Elaborado pelos autores (2016) 
Foram encontrados 75 autores, dos quais apenas dois autores aparecem em mais de um artigo, totalizando dois artigos para cada dois autores. O autor André Luiz Emmel Silva aparece com dois artigos publicados, um em 2014 e outro em 2015. Outro autor é Jacques Demajorovic com artigos publicados em 2012 e 2015. Dentre os autores os de gênero masculino prevaleceram em relação ao feminino, com $61,4 \%$ do total.

Na distribuição dos autores por artigo, foram encontrados artigos de um autor até o máximo de seis autores. De acordo com o Quadro 2, a menor quantidade de artigos encontrados foi apenas um artigo com seis autores e máximo encontrado foram sete artigos contendo três autores.

QUADRO 2 - Quantidade de autores por artigo
encontrados em publicações com o
tema Logística Reversa durante os
anos de 2011 a 2015
\begin{tabular}{|c|c|}
\hline Quantidade de Autores & Quantidade de Artigos \\
\hline 1 & 2 \\
\hline 2 & 5 \\
\hline 3 & 7 \\
\hline 4 & 4 \\
\hline 5 & 4 \\
\hline 6 & 1 \\
\hline Total & 23 \\
\hline
\end{tabular}

FONTE: Elaborado pelos autores (2016)

Todos os autores encontrados estavam vinculados a alguma instituição. Foram encontradas no total 26 instituições, das quais apenas uma não é brasileira, mas cubana. Como demonstra o Quadro 3, as instituições com a maior quantidade de autores foram o Centro Universitário da FEI, UNISC, UFRJ e UNISINOS.

QUADRO 3 - Instituições por autores encontrados em publicações com o tema Logística Reversa durante os anos de 2011 a 2015

\begin{tabular}{|l|c|}
\hline \multicolumn{1}{|c|}{ Instituição } & Autores \\
\hline Faculdade Anhanguera & 2 \\
\hline Centro Universitário FEI & 13 \\
\hline Universidade FUMEC & 1 \\
\hline FURB - Universidade Regional de Blumenau & 2 \\
\hline Faculdade INPG & 1 \\
\hline UCLV - Universidad Central Marta Abreu de Las Villas & 1 \\
\hline UCS - Universidade de Caxias do Sul & 3 \\
\hline UEFS - Universidade Estadual de Feira de Santana & 1 \\
\hline UERJ - Universidade do Estado do Rio de Janeiro & 2 \\
\hline UFABC - Universidade Federal do ABC & 1 \\
\hline UFBA - Universidade Federal da Bahia & 2 \\
\hline UFES - Universidade Federal do Espírito Santo & 1 \\
\hline UFF - Universidade Federal Fluminense & 3 \\
\hline UFPE - Universidade Federal do Pernambuco & 2 \\
\hline UFPI - Universidade Federal do Piauí & \\
\hline
\end{tabular}




\begin{tabular}{|l|l|} 
UFRGS - Universidade Federal do Rio Grande do Sul & 4 \\
\hline UFRJ - Universidade Federal do Rio de Janeiro & 5 \\
\hline UFS - Universidade Federal de Sergipe & 2 \\
\hline UFU - Universidade Federal de Uberlândia & 3 \\
\hline ULBRA - Universidade Luterana do Brasil & 1 \\
\hline UNESP - Universidade Estadual Paulista & 1 \\
\hline UNINOVE - Universidade Nove de Julho & 3 \\
\hline UNIRIO - Universidade Federal do Estado do Rio de Janeiro & 1 \\
\hline UNISC - Universidade de Santa Cruz do Sul & 9 \\
\hline UNISINOS - Universidade do Vale do Rio dos Sinos & 5 \\
\hline USP - Universidade de São Paulo & 2 \\
\hline
\end{tabular}

FONTE: Elaborado pelos autores (2016)

Das 26 instituições encontradas, 15 são da região sudeste do Brasil, cinco da região sul, cinco do nordeste e uma de Cuba. Não foi encontrado nenhum autor vinculado a instituições do norte, centro-oeste e Distrito Federal do Brasil. Partindo para os temas pesquisados dentro da Logística Reversa nos artigos encontrados, houve uma grande diversidade de ramos pesquisados. No artigo de LOPES et al. (2014), único publicado em inglês, foi realizada uma pesquisa de campo com três lojas de departamento e propuseram um procedimento estruturado para gestão da cadeia logística reversa de bens de pós-venda. Já CORRÊA \& SILVA (2013) analisaram o processo de Logística Reversa de produtos pós-consumo da empresa O Boticário. Constatou-se que este processo precisa ser mais bem comunicado para uma maior participação do consumidor, pois este consumidor mostra interesse pelo processo.

DEMAJOROVIC et al., (2012) em seus resultados evidenciaram que as empresas de baterias e celulares não estão alinhadas com a legislação vigente, pois a Lei no 12.305 obriga estas empresas a estruturar programas de Logística Reversa e a comunicar seus clientes como proceder após a vida útil de seus produtos.

Os autores LADEIRA et al. (2012) verificaram quais são os principais fatores que levam produtores rurais a realizarem a logística reversa de embalagens de defensivos agrícolas. Na mesma direção DORION et al. (2011) analisaram a Logística Reversa de embalagens de insumos agrícolas apoiada pela tecnologia da informação em uma grande empresa que produz maçãs na região Sul do Brasil. Destacou-se nos resultados que a implantação de um sistema de informação específico permitiu o gerenciamento eficaz, seguro e rápido dos processos de logística, aplicação e logística reversa de insumos e mudas. FERRI et al. (2015) realizaram um estudo de caso em São Mateus-ES propondo a localização de centros de armazenamento e triagem de Resíduos Sólidos Urbanos (RSU).

SILVA \& MOITA NETO (2011) analisaram a viabilidade da Logística Reversa nas indústrias do setor de plásticos em Teresina-PI e constataram que a aplicação da mesma está distante no setor. A pesquisa foi realizada em nove indústrias do setor e o estabelecimento da logística reversa depende de atividades de pesquisa e inovação tecnológica e da criação de um mercado para produtos reciclados. TENÓRIO et al. (2014) buscaram entender o gerenciamento da etapa de retorno de embalagens plásticas ao ciclo produtivo em uma rede de empresas da indústria plástica de Alagoas. Nos resultados depararam com um processo composto por atividades sequenciais, através de três empresas, onde observaram uma hierarquia 
informal, interdependência física e financeira, auto-organização e compartilhamento de informações.

DEMAJOROVIC \& SENCOVICI (2015) identificaram os principais desafios e perspectivas para a implantação da Logística Reversa para o óleo lubrificante usado e para a embalagem. Mostraram resultados positivos como avanços tecnológicos que permitem gerar um óleo rerrefinado representando ganhos econômicos e socioambientais e avanços nas embalagens e aspectos negativos como conflitos de distribuição de custos na cadeia reversa, falta de soluções regionais para a reciclagem, precária fiscalização, ausência de incentivos tributários e baixo interesse de fabricantes em privilegiar a prevenção.

ARAÚJO et al., (2013) relataram o processo de Logística Reversa do maior varejista virtual do Brasil, mostraram a evolução, analisaram desempenho e identificaram as principais deficiências e apresentaram também sugestões para melhorias e implantação de um sistema mais eficiente.

HERNÁNDEZ et al. (2012) realizaram um estudo em empresas que representam nove ramos da economia e que apresentam alguma prática de Logística Reserva, tais como: automobilística, editorial, eletrodoméstico, farmacêutico, metalúrgico, informático e material de construção. Como resultado apresentaram um modelo conceitual que inclui indicadores de desempenho da atividade de Logística Reversa.

SILVA et al. (2015) exploraram o impacto ambiental da produção de uma empresa fabricante de conjuntos de chuva para motociclistas situada no Rio Grande do Sul. Como resultado foi elaborada uma proposta de Produção Mais Limpa, voltada às práticas de ecodesign e Logística Reversa e a proposta atingiu os objetivos de forma ágil, desburocratizada e com custo baixo.

OLIVEIRA NETO et al. (2014) analisaram as vantagens ambientais e econômicas de um processo de Logística Reversa de vidros impressos de uma grande empresa do setor e constataram que a empresa obteve um ganho ambiental de $131,86 \mathrm{~kg}$ de material retirado do meio ambiente e vantagem econômica de 37,4\% da receita líquida média total com a reutilização de embalagens e reuso dos cacos de vidro.

Já abordando a Logística Reversa junto com a Política Nacional de Resíduos Sólidos, THODE FILHO et al., (2015) apresentaram através de pesquisa qualitativa uma evolução das práticas de Logística Reversa e em paralelo a implementação da Política Nacional de Resíduos Sólidos (PNRS) e sua adequação, porém tal crescimento não foi relevante diante do constante crescimento do consumo e geração de resíduos pela população do Brasil. Já PEREIRA NETO (2011) abordou as principais características da PNRS relacionadas ao instrumento da Logística Reversa, também o papel, oportunidades e exigências impostas aos catadores de materiais reciclados. A autora MARCHI (2011) fez uma reflexão da conexão existente entre o rigor da PNRS e as práticas cotidianas dos serviços de limpeza dos municípios brasileiros. Também apresentou o cenário mundial de descarte de Resíduos Sólidos Urbanos e o desenvolvimento da Logística Reversa na indústria nacional.

PEREIRA \& PEREIRA (2011) relacionaram a edição da Lei 12.305/2010, que aborda a gestão dos Resíduos Sólidos Urbanos, com a Logística Reversa de Resíduos de Serviços de Saúde para os hospitais públicos mineiros, o papel e as responsabilidades do setor público e iniciativa privada, onde constataram que estes hospitais ainda precisam de uma grande readequação para atender a legislação em questão. 
SANTOS et al., (2013) investigaram a contribuição da Logística Reversa nas etapas de gerenciamento adequado dos pneus pós-consumo e trouxeram como resultado as vantagens para a sustentabilidade ambiental como possibilidade da reciclagem, economia de recursos naturais, economia de recursos energéticos na fabricação e economia de outros tipos de combustíveis. E LAGARINHOS \& TENÓRIO (2013) retrataram legislação pertinente a Logística Reversa dos pneus usados no Brasil e compararam com sistemas utilizados no Japão, Estados Unidos e Comunidade Europeia.

SELLITTO et al., (2013) através de estudo de caso descreveram um fabricante de cimento que implantou e consolidou o coprocessamento de pneus e casca de arroz através da Logística Reversa, utilizados como combustível alternativo. Um ponto importante foi o ganho ambiental de redução de 10 mil toneladas de combustível fóssil que gerava cerca de 30 mil toneladas de $\mathrm{CO}_{2}$ por ano. VARGAS et al., (2014) abordaram a Logística Reversa de lâmpadas fluorescentes em empresa de painéis de madeira aglomerada no Rio Grande do Sul e se atendiam aos requisitos da PNRS e da certificação ISO 14000 que a empresa almeja.

SILVA et al., (2012) fizeram uma reflexão da integração da Logística Reversa e Responsabilidade Social Corporativa no Brasil, que traz um perfil necessário mais ligado a valores universais especialmente jurídico e ética. E por fim, no artigo de VALANDRO et al., (2012), foi realizada uma análise bibliométrica a respeito de Logística Reversa no período de 2003 a 2012, na busca encontraram 61 artigos em 36 periódicos diferentes.

\section{CONCLUSÃO}

Este estudo bibliométrico analisou as publicações de artigos com o tema Logistica Reversa publicados de 2011 a 2015 nos periódicos nacionais onde verificou uma variedade de periódicos publicando sobre o tema. Percebe-se que a Logística Reversa pode ser aplicada em vários setores da economia, mas demonstra ainda muitas barreiras e necessidades para se adequar. Muitos artigos relacionaram o tema com legislação pertinente e principalmente a criação da Política Nacional de Resíduos Sólidos, que foi um marco para a Logística Reversa no Brasil.

Muitos artigos também relacionam o tema com reciclagem de materiais, demonstrando assim uma sustentabilidade e responsabilidade socioambiental por parte das empresas pesquisadas.

Esta pesquisa trouxe dados importantes consolidando a Logística Reversa por pesquisadores em publicações nacionais e sendo parte de estratégias de empresas de vários setores, mas ainda deixa lacunas a serem preenchidas por falta de informações, falta de fiscalização, meios físicos e financeiros para a implantação da mesma.

\section{REFERÊNCIAS}

ARAUJO, A. C.; MATSUOKA, E. M.; UNG J. E.; HILSDORF, W. C.; SAMPAIO, M. Logística reversa no comércio eletrônico: um estudo de caso. Gestão \& Produção, São Carlos, v. 20, n. 2, p. 303-320, jun. 2013. Disponível em <http://www.scielo.br/scielo.php?script=sci_arttext\&pid=S0104-

530X2013000200005\&lng=pt\&nrm=iso>. Acesso em: 01 set. 2016. http://dx.doi.org/10.1590/S0104-530X2013000200005. 
BRAGA, G. M. Informação, ciência, política científica: o pensamento de Derek de Solla Price. Ciência da Informação, Brasília, v. 3, n. 2, p. 155-177, 1974.

BRASIL. Casa Civil. Lei $\mathbf{n}^{\circ} \mathbf{1 2 . 3 0 5}$ de 02 de agosto de 2010. Institui a Política Nacional de Resíduos Sólidos; altera a Lei no 9.605, de 12 de fevereiro de 1998; e dá outras providências. 2010.2 Disponível em: <http://www.planalto.gov.br/ccivil_03/_ato2007-2010/2010/lei/l12305.htm> Acesso em: 16 de Agosto de 2016

CHAVES, G. L. D.; ALCÂNTARA, R. L. C.; ASSUMPÇÃO, M. R. P. Medidas de desempenho na logística reversa: o caso de uma empresa do setor de bebidas. Relatórios de Pesquisa em Engenharia de Produção, Niterói, v.8, 2008.

CHAVES, G. L. D.; BATALHA, M. O. Os consumidores valorizam a coleta de embalagens recicláveis? Um estudo de caso da logística reversa em uma rede de hipermercados. Gestão \& Produção, São Carlos, v. 13, n. 3, p. 423-434, Dez. 2006. Disponível em: <http://www.scielo.br/scielo.php?script=sci_arttext\&pid=S0104530X2006000300006\&lng=en\&nrm=iso >. Acesso em: 2 de Agosto de 2016.

CORRÊA, A.; SILVA, M. A Logística Reversa Sob a Perspectiva Produção-MercadoConsumo: O Caso O Boticário. Revista de Gestão Ambiental e Sustentabilidade GeAS, v. 2, n. $\quad$ 1, 2013. Disponível em: <http://www.revistageas.org.br/ojs/index.php/geas/article/view/36>. Acesso em: 16 Set. 2016.

CORRÊA, H. L. Gestão da rede de suprimentos: integrando cadeias de suprimento. 3aㅗ ed. São Paulo: Atlas, 2010.

DE BRITO, M. P. Managing reverse logistics or reversing logistics management? 2004. 327. Erasmus University Rotterdam, Netherlands. Disponível em: <repub.eur.nl/pub/1132/EPS2004035LIS_9058920585_DEBRITO.pdf> Acesso em: 3 de Setembro de 2016.

DEMAJOROVIC, J.; HUERTAS, M. K. Z.; BOUERES, J. A.; SILVA, A. G.; SOTANO, A. S. Logística reversa: como as empresas comunicam o descarte de baterias e celulares? Revista Administração empresarial, São Paulo, v. 52, n. 2, p. 165178, abr, 2012. Disponível em <http://www.scielo.br/scielo.php?script=sci_arttext\&pid=S0034-

75902012000200004\&lng=pt\&nrm=iso>. Acesso em: 03 set. 2016. http://dx.doi.org/10.1590/S0034-75902012000200004.

DEMAJOROVIC, J.; SENCOVICI, L. A. Entraves e perspectivas para a logística reversa do óleo lubrificante e suas embalagens. Revista Gestão Ambiental e Sustentabilidade, v. 4, n.2. Agosto, 2015. Disponível em: < http://www.revistageas.org.br/ojs/index.php/geas/article/view/167/pdf> Acesso em: 01 de Set., 2016. DOI: 10.5585/geas.v4i2.167

DORION, E. C. H.; DE ABREU, M. F.; SEVERO, E. A. A Contribuição da Logística Reversa e dos Sistemas de Informação na Busca Pela Sustentabilidade Ambiental. Revista de Administração IMED, v. 1, n. 1, p. 97-122, dez. 2011. ISSN 
2237-7956.

Disponível

em:

<https://seer.imed.edu.br/index.php/raimed/article/view/72/63>. Acesso em: 16 set. 2016. doi:http://dx.doi.org/10.18256/2237-7956/raimed.v1n1p97-122.

FERRI, G. L.; CHAVES, G. L. D.; RIBEIRO, G. M. Análise e localização de centros de armazenamento e triagem de resíduos sólidos urbanos para a rede de logística reversa: um estudo de caso no município de São Mateus, ES. Production, São Paulo, v. 25, n. 1, p. 27-42, mar. 2015.2 Disponível em $<$ http://www.scielo.br/scielo.php?script=sci_arttext\&pid=S0103-

65132015000100027\&lng=pt\&nrm=iso >. Acesso em: 02 set., 2016. http://dx.doi.org/10.1590/S0103-65132014005000014.

GONCALVES, M. E.; MARINS, F. A. S. Logística reversa numa empresa de laminação de vidros: um estudo de caso. Gestão \& Produção, São Carlos, v. 13, n. 3, p. 397-410, $2006 . \quad$ Disponível em: $<$ http://www.scielo.br/scielo.php?script=sci_arttext\&pid=S0104-

530X2006000300004\&Ing=en\&nrm=iso>. Acesso em: 16 Set., 2016. http://dx.doi.org/10.1590/S0104-530X2006000300004.

GUARNIERI, P., KOVALESKI, J. L., STADLER, C. C., OLIVEIRA, I. V. A caracterização da logística reversa no ambiente empresarial em suas áreas de atuação: pós-venda e pós-consumo agregando valor econômico e legal. Tecnologia \& Humanismo, Curitiba, v. 19, n.1, p. 120-131, 2005. Disponível em: <http://www.resol.com.br/textos/e-book_2006_artigo_57.pdf>. Acesso em: 13 de Setembro de 2016.

HERNANDEZ, C. T.; MARINS, F. A. S.; CASTRO, R. C. Modelo de Gerenciamento da Logística Reversa. Gestão \& Produção, São Carlos, v. 19, n. 3, p. 445-456, 2012. Disponível em: <http://www.scielo.br/scielo.php?script=sci_arttext\&pid=S0104530X2012000300001\&lng=pt\&nrm=iso> . acessos em 01 set. 2016. http://dx.doi.org/10.1590/S0104-530X2012000300001.

LADEIRA, W. J.; MAEHLER, A. E.; NASCIMENTO, L. F. M. Logística Reversa de Defensivos Agrícolas: fatores que influenciam nas consciência ambiental de agricultores gaúchos e mineiros. Revista de Economia e Sociologia Rural - RESR, v 50, n. 1, p. 157-174, 2012. Disponível em: <http://www.scielo.br/pdf/resr/v50n1/a09v50n1.pdf> Acesso em: 28 de Agosto, 2016.

LAGARINHOS, C. A. F.; TENÓRIO, J. A. S. Logística Reversa dos pneus usados no Brasil. Polímeros, São Carlos, v. 23, n. 1, p. 49-58, 2013. Disponível em $<$ http://www.scielo.br/scielo.php?script=sci_arttext\&pid=S010414282013000100012\&lng=pt\&nrm=iso >. Acesso em: 03 set. 2016.

LEITE, P. R. Logística Reversa: Nova área da Logística Empresarial. São Paulo: Ed. Publicare, 2002. Disponível em: http://meusite.mackenzie.br/leitepr/LOG\%CDSTICA\%20REVERSA\%20\%20NOVA\%20\%C1REA\%20DA\%20LOG\%CDSTICA\%20EMPRESARIAL.pdf>. Acesso em: 11 de Agosto de 2016. 
LEITE, P. R. Logística reversa: meio ambiente e competitividade. 2. ed. São Paulo: Pearson, 2009.

LOPES, D. M. M.; D'AGOSTO, M. A.; FERREIRA, A. F.; OLIVEIRA, C. M. Improving post-sale reverse logistics in department stores: a Brazilian case study. Journal of Transport Literature, Manaus, v. 8, n. 2, p. 325-348, abr. 2014 . Disponível em <http://www.scielo.br/scielo.php?script=sci_arttext\&pid=S2238-

10312014000200014\&lng=pt\&nrm=iso>. Acesso em: 01 de Setembro, 2016.

MARCHI, C. M. D. F. Cenário Mundial dos Resíduos Sólidos e o comportamento corporativo brasileiro frente à logística reversa. Revista Perspectivas em Gestão \& Conhecimento. V. 1, p. 118-135, 2011. Disponível em: < http://periodicos.ufpb.br/ojs/index.php/pgc/article/view/9062/6907>. Acesso em: 02 de Setembro, 2016.

MEIS, L.; MAIA, C.; LANNES, D.; MACHADO, R. P. Uso de indicadores exige cautela. Folha de São Paulo, São Paulo, 12 set. 1999. Caderno Especial Ranking da Ciência, p. 7.

OLIVEIRA NETO, G. C; SOUZA, M. T. S.; SILVA, D.; SILVA, L. A. Avaliação das vantagens ambientais e econômicas da implantação da logística reversa no setor de vidros impressos. Ambiente \& Sociedade, São Paulo, v. 17, n. 3, p. 199-220, set. 2014. Disponível

em <http://www.scielo.br/scielo.php?script=sci_arttext\&pid=S1414753X2014000300012\&lng $=$ pt\&nrm $=$ iso $>$. $\quad$ Acesso em: 01 set., 2016. http://dx.doi.org/10.1590/S1414-753X2014000300012.

PEREIRA, A. L.; PEREIRA, S. R. A cadeia de logística reversa de resíduos de serviços de saúde dos hospitais públicos de Minas Gerais: análise a partir dos conceitos da nova Política Nacional de Resíduos Sólidos Urbanos. Desenvolvimento e Meio Ambiente, n. 24, p. 185-199, 2011. Disponível em: < http://revistas.ufpr.br/made/article/viewFile/21005/17088> Acesso em: 01 de Set., 2016.

PEREIRA NETO, T. J. A Política Nacional de Resíduos Sólidos: os reflexos nas cooperativas de catadores e a logística reversa. Revista Diálogo. N. 8. P. 77-96. $2011 . \quad$ Disponível em: <http://revistas.unilasalle.edu.br/index.php/Dialogo/article/view/104/121>. Acesso em: 30 de Agosto, 2016.

SANTOS, L. A. A.; BOTINHA, R. A.; LEAL, E. A. A contribuição da logística reversa de pneumáticos para a sustentabilidade ambiental. Revista de Administração, Contabilidade e Economia, v. 12, n. 2, p. 339-370, 2013. ISSN 2179-4936. Disponível em: <http://editora.unoesc.edu.br/index.php/race/article/view/1709>. Acesso em: 01 Set. 2016.

SELLITTO, M. A.; KADEL JR., N.; BORCHARDT, M.; PEREIRA, G. M.; DOMINGUES, J. Coprocessamento de cascas de arroz e pneus inservíveis e logística reversa na fabricação de cimento. Ambiente \& Sociedade, São Paulo, v. 
$16, \mathrm{n}$.

$1, \mathrm{p}$.

141-162, 2013.

Disponível

em:

<http://www.scielo.br/scielo.php?script=sci_arttext\&pid=S1414-

753X2013000100009\&lng=pt\&nrm=iso >. Acesso em: 01 set., 2016. http://dx.doi.org/10.1590/S1414-753X2013000100009.

SILVA, A. L. E.; MORAES, J. A. R.; MACHADO, E. L. Proposta de produção mais limpa voltada às práticas de ecodesign e logística reversa. Engenharia Sanitária e Ambiental, Rio de Janeiro , v. 20, n. 1, p. 29-37, mar. 2015. Disponível em <http://www.scielo.br/scielo.php?script=sci_arttext\&pid=S1413-

41522015000100029\&lng=pt\&nrm=iso>. Acesso em: 16 set., 2016. http://dx.doi.org/10.1590/S1413-41522015020000087843.

SILVA, E. A.; MOITA NETO, J. M. Logística reversa nas indústrias de plásticos de Teresina-PI: um estudo de viabilidade. Polímeros, São Carlos, v. 21, n. 3, p. 246251, $2011 . \quad$ Disponível <http://www.scielo.br/scielo.php?script=sci_arttext\&pid=S010414282011000300015\&lng=pt\&nrm=iso >. Acesso em: 02 set., 2016. http://dx.doi.org/10.1590/S0104-14282011005000041.

SILVA, R. O.; SALUN, A. O.; SANTOS, J. P.; JOINHAS, L. A. Elementos para uma nova compreensão da logística reversa: direito, valores humanos e negócios. Lex Humana, v. 4, n. 2, nov. 2012. ISSN 2175-0947. Disponível em: $<$ http://seer.ucp.br/seer/index.php?journal=LexHumana\&page=article\&op=view\&path $\% 5 B \% 5 D=261 \&$ path\%5B\%5D=184>. Acesso em: 02 Set. 2016.

TENÓRIO, F. A.; REIS, A. F.; SILVA, D. E.; LUFT, M. C. M. S. Redes de logística reversa: um estudo do canal reverso de reciclagem na indústria do plástico. Revista de Administração, Contabilidade e Economia, v. 13, n. 1, p. 353-382, jan. 2014. ISSN 2179-4936. Disponível em: <http://editora.unoesc.edu.br/index.php/race/article/view/3552>. Acesso em: 03 Set. 2016.

THODE FILHO, S.; MACHADO; C. J. S.; VILANI, R. M.; PAIVA, J. L.; MARQUES, M. R. C. A Logística Reversa e a Política Nacional de Resíduos Sólidos: desafios para a realidade brasileira. Revista Eletrônica em Gestão, Educação e Tecnologia Ambiental, v. 19, p. 529-538, 2015. Disponível em: <https://periodicos.ufsm.br/reget/article/viewFile/19322/pdf>. Acesso em: 30 de Agosto, 2016. DOI: 105902/2236117019322

VALANDRO; F. D.; SILVA, M. Z.; SILVA, J. C. Logística Reversa: análise bibliométrica de artigos publicados em periódicos brasileiros no período de 2003 a 2012. Evidenciação Contábil \& Finanças, 2014, v. 3, n. 2, p. 56-72. Disponível em: <http://periodicos.ufpb.br/ojs/index.php/recfin/article/view/16933/11960> Acesso em: 04 de Setembro, 2016. DOI: 10.18405/recfin20140304.

VARGAS, P. R.; BONI; G.; SILVA, A. L. E.; NARA, E. O. B.; REDISKE, G.; KIPPER, L. M. Uma analogia entre a Logística Reversa, ISSO 14000, e a Política Nacional de Resíduos Sólidos no Brasil. Holos Environment (Online), v. 14, p. 222-231, 2014. Disponível em: <https://www.researchgate.net/publication/274082246_Uma_Analogia_entre_a_Logi 
stica_Reversa_ISO_14000_e_a_Politica_Nacional_de_Residuos_Solidos_no_Brasil > Acesso em: 02 de Set. 2016. 